\title{
EDUKASI PERSIAPAN PERSALINAN PADA PASANGAN HAMIL DALAM MENYAMBUT PERSALINAN MINIM TRAUMA
}

DOI: https://doi.org/10.33024/jkpm.v4i5.4247

Lisa Trina Arlym ${ }^{*}$, Yulia Herawati

${ }^{1}$ Program Studi Sarjana Terapan Kebidanan, STIKes Mitra RIA Husada

Disubmit: 20 April 2021 Diterima: 04 Mei 2021 Diterbitkan: 01 Oktober 2021

Email Korespondensi: lisatrinaarlym@gmail.com

\begin{abstract}
ABSTRAK
Psikologis ibu dalam hal ini kecemasan dapat mempengaruhi kemajuan persalinan. Edukasi persalinan dilakukan untuk mempersiapkan ibu dalam menghadapi persalinan secara fisik dan khususnya persiapan psikologis. Edukasi dianggap cara terbaik dalam mempersiapkan persalinan. Kegiatan ini bertujuan untuk meningkatkan pengetahuan ibu hamil dan pasangannya di PMB Jeanne Kota Depok. Metode yang digunakan adalah presentasi dan simulasi pada kelas ibu hamil, dilakukan juga variasi kegiatan secara outdoor dan indoor agar penyampaian lebih menarik. Hasil dari kegiatan ini efektif, terlihat antusias peserta dalam mengajukan pertanyaan. Peserta edukasi menyatakan lebih siap dan mengerti dalam menghadapi persalinan. Diharapkan kelas edukasi dapat dilaksanakan secara periodik sehingga lebih banyak lagi pasangan yang teredukasi dan siap menghadapi kehamilan dan persalinan dengan nyaman dan minim trauma.
\end{abstract}

Kata kunci: kehamilan; pendidikan saat hamil; edukasi persalinan

\begin{abstract}
Psychologically, in this case, anxiety can affect the progress of labor. Childbirth education is carried out to prepare mothers for physical delivery and especially psychological preparation. Education is considered the best way to prepare for labor. This activity aims to increase knowledge of pregnant couples at PMB Jeanne Depok City. The methods used are presentations and class simulations for pregnant women, as well as a variety of outdoor and indoor activities so that the delivery was more interesting. The results of this activity were effective, it was seen that the participants were enthusiastic in asking questions. Educational participants were more prepared and understanding in dealing with childbirth. It is hoped that education classes can be carried out periodically so that more couples are educated and ready to face pregnancy and childbirth comfortably and with minimal trauma.
\end{abstract}

Key words: pregnancy; education during pregnancy; childbirth education 


\section{PENDAHULUAN}

Setiap ibu hamil menghadapi risiko terjadinya kematian, sehingga salah satu upaya menurunkan tingkat kematian ibu adalah meningkatkan status kesehatan ibu hamil sampai bersalin melalui pelayanan ibu hamil sampai masa nifas (Kemenkes, 2013). Kehamilan, persalinan dan nifas merupakan periode kehidupan yang normal yang dialami oleh setiap perempuan. WHO menyatakan hanya sepuluh persen $(10 \%)$ dari kehamilan, persalinan dan nifas berjalan tidak normal yang memerlukan tindakan medis.

Proses kehamilan dan persalinan memerlukan persiapan baik secara fisik maupun psikologis. Kesiapan fisik meliputi matangnya sistem reproduksi, kebutuhan nutrisi, personal hygiene. Kesiapan psikologis adalah dimana seorang perempuan dan pasangannya merasa telah ingin mempunyai anak dan merasa telah siap menjadi orang tua termasuk mengasuh dan mendidik anaknya. Dukungan dan peran serta suami dalam masa kehamilan terbukti meningkatkan kesiapan ibu hamil dalam menghadapi proses persalinan, bahkan juga memicu produksi ASI (Hodnett et al., 2014).

Komponen penting dalam proses persalinan adalah passageway (jalan lahir), passenger (janin), power (kekuatan kontraksi), pelvic/position (posisi ibu), placenta dan psyche (psikologis ibu) serta penolong (Mochtar, 2011). Penyulit dapat terjadi ketika komponen diatas tidak berjalan sebagaimana mestinya. Setiap tahap persalinan terjadi perubahan fisik dan psikologis. Penelitian yang dilakukan Tumblin dan Simkin (2001) tentang persepsi ibu hamil tentang peran perawat/bidan ketika persalinan menyimpulkan bahwa ibu mengharapkan perawat menyediakan waktu untuk memberi rasa nyaman, dukungan emosional dan dukungan informasi (Sunarti \& Soejono, 2012). Rasa takut atau senang dan kesiapannya menghadapi persalinan mempengaruhi kemajuan persalinan (Bobak et al., 2005).

Edukasi dianggap cara terbaik dalam mempersiapkan persalinan (Ip et al., 2003). Edukasi pada ibu hamil dapat mempengaruhi cara persalinan (Afshar et al., 2017). Penelitian menyebutkan bahwa program persiapan persalinan akan meningkatkan kepuasaan ibu dalam menghadapi persalinan, dapat berkomunikasi lebih baik dengan penyedia layanan, berpartisipasi dalam pengambilan keputusan selama persalinan dan mengurangi persepsi nyeri persalinan (Akca et al., 2017; Serçekuş \& Bașkale, 2016). Studi kualitatif di Brazil menemukan bahwa ibu yang mengikuti kelas edukasi dalam kehamilan, lebih dapat mengendalikan diri selama persalinan dan menggunakan latihan pernafasan, latihan dengan bola persalinan serta posisi tegak untuk mengontrol rasa nyeri selama persalinan (Miquelutti et al., 2013).

Kelas edukasi persalinan dilakukan untuk mempersiapkan ibu dalam menghadapi persalinan secara fisik dan khususnya persiapan psikologis. Rendahnya kepercayaan ibu, rasa takut, stress dan trauma menunjukkan perbaikan setelah mengikuti kelas edukasi persalinan. Hal ini dianggap penting karena dapat mewujudkan proses kehamilan dan persalinan yang aman, nyaman dan minim trauma (Byrne et al., 2014). Kelas edukasi mempertemukan ibu dengan ibu lain dengan situasi yang sama dan mengembangkan jejaring (Brixval et al., 2015). Ibu yang mendapatkan dukungan pada masa persalinan akan berpeluang untuk bisa melahirkan normal lebih tinggi dan minimal intervensi (Hodnett et al., 2014). Oleh karena itu perlu dilakukan kegiatan kelas edukasi persiapan persalinan pada pasangan hamil sehingga dapat menyambut kelahiran dengan nyaman dan aman. 


\section{MASALAH}

Bidan Praktek Mandiri (PMB) merupakan salah satu fasilitas kesehatan yang digemari oleh ibu hamil karena merasa lebih dekat dan diperhatikan dibandingkan dengan layanan kesehatan lain. Hasil studi pendahuluan di PMB Bidan Jeanne didapatkan bahwa 4 dari 5 ibu merasa takut dan cemas dalam menghadapi persalinannya, mereka menginginkan suami terlibat dalam proses persalinannya sehingga ibu mendapatkan dukungan dari suami.

Alasan kami memilih tempat kegiatan adalah PMB Jeanne melayani pasien hanya sebatas pelayanan standar, belum pernah dilakukan kegiatan edukasi persiapan persalinan dan pasien-pasien sangat berharap diadakan kelas edukasi dalam rangka mempersiapkan fisik dan psikologis untuk menghadapi proses persalinan.

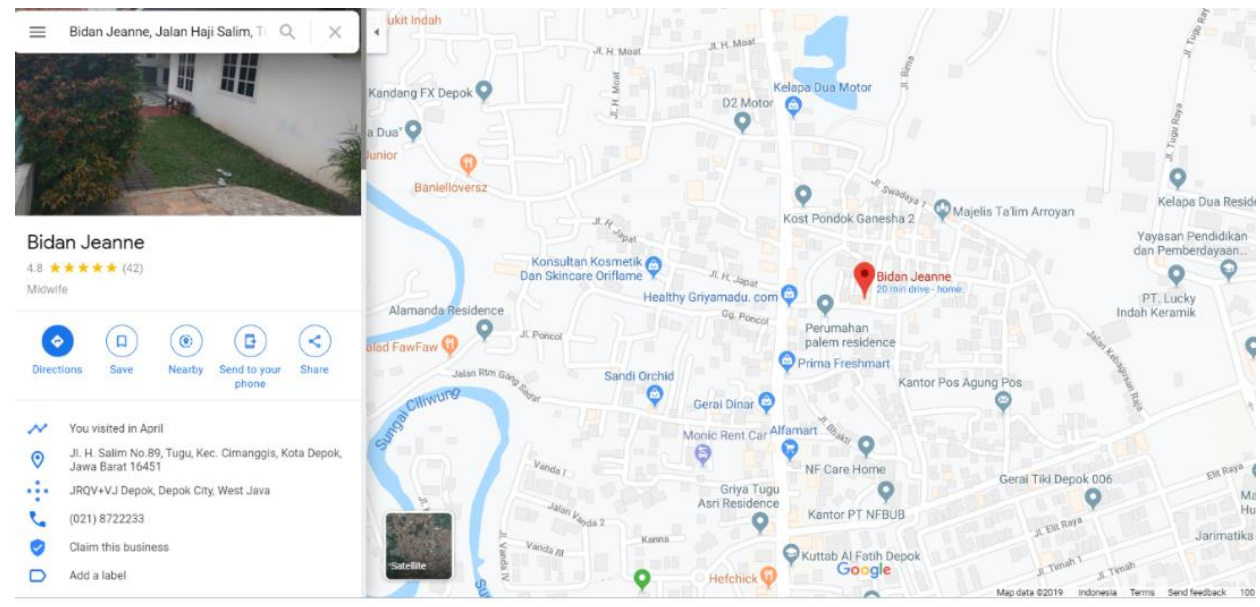

Gambar 2.1 Map lokasi kegiatan pengabdian kepada masyarakat

\section{METODE}

Metode yang digunakan adalah presentasi dan simulasi pada kelas ibu hamil di PMB Jeanne Kota Depok. Materi presentasi disajikan dalam bentuk presentasi PPT dengan alat bantu, kemudian dilanjutkan dengan simulasi posisi persalinan, optimalisasi posisi janin, teknik mengurangi rasa nyeri dan endorfin massage. Kegiatan ini diadakan secara outdoor dan indoor di PMB Jeanne pada hari Sabtu, 10 Agustus 2019. Peserta yang hadir yaitu ibu hamil dengan pasangannya sebanyak 16 orang. Kegiatan ini dibantu oleh mahasiswa dan bidan.

Adapun kegiatan yang dilakukan pada pengabdian kepada masyarakat ini dilakukan dengan metode presentasi, tanya jawab kemudian dilanjutkan dengan praktik. Presentasi dilakukan untuk menjelaskan teori tentang kehamilan dan teori persalinan. Teori tentang kehamilan meliputi meliputi; perubahan yang terjadi pada masa kehamilan, ketidaknyamanan dan kebutuhan ibu selama masa kehamilan, nutrisi kehamilan dan menyiapkan tubuh dalam menghadapi persalinan.

Sedangkan teori tentang persalinan terdiri dari tujuan persalinan, tahapan persalinan, perubahan yang terjadi pada masa persalinan, hormon pada persalinan, faktor yang mempengaruhi persalinan, posisi melahirkan, gambaran proses persalinan, menjaga lingkungan melahirkan, intuisi, peran tim kelahiran, komplikasi 
persalinan, meminimalisir intervensi medis, teknik mengurangi rasa nyeri dan peran pendamping dalam persalinan. Kegiatan praktik pada pengabdian kepada masyarakat ini dilakukan dengan mempraktekkan gambaran melahirkan, posisi persalinan, teknik mengurangi rasa nyeri dan endorfin massage.

\section{HASIL DAN PEMBAHASAN}

Kegiatan edukasi ini diberjalan selama kurang lebih 1,5 jam dengan dihadiri oleh delapan pasangan ibu hamil usia kehamilan 26 minggu sd 36 minggu. Edukasi yang dilakukan dengan metode presentasi efektif dilakukan, hal ini terlihat dalam proses kegiatan dimana peserta sangat antusias dan adanya tanya jawab dari materi yang disampaikan. Edukasi dengan metode praktek pun juga efektif, terlihat dari keikutsertaan peserta dalam melakukan kegiatan praktek.

Edukasi yang diberikan dalam pengabdian kepada masyarakat ini dapat menambah pemahaman ibu dalam mempersiapkan kehamilan dan persalinannya sehingga ibu merasa lebih siap dan menurunkan kecemasannya dalam menghadapi persalinan. Suami yang mengikuti edukasi juga menjadi lebih siap dan mengerti apa yang harus dilakukan ketika mendampingi istrinya dalam proses persalinan. Secara keseluruhan apa yang menjadi kecemasan dalam menghadapi persalinan dapat diatasi oleh pasangan ibu hamil.

Kehamilan merupakan proses alamiah yang dialami oleh setiap perempuan. Selama kehamilan, tubuh ibu mengalami banyak perubahan. Perubahan yang terjadi secara fisik maupun psikologis. Akibat perubahan fisik pada ibu hamil seringkali membuat ibu merasa tidak nyaman (Bobak et al., 2005). Perubahan hormonal pada ibu hamil mempengaruhi psikologis ibu. Ketidakmampuan ibu hamil mengatasi ketidaknyamanan akibat perubahan fisiologis juga dapat membuat psikologis ibu terganggu (Irianti et al., 2014). Kegiatan edukasi ini menjelaskan tentang perubahan pada masa hamil, ketidaknyamanan dan kebutuhan ibu selama hamil sehingga ibu menjadi lebih siap.

Gangguan psikologis dapat berupa kecemasan, kekhawatiran dalam kehamilan dan menghadapi persalinan yang pada akhirnya bisa menyebabkan stress. Berdasarkan penelitian Robinson dkk (2010) dalam (Irianti et al., 2014) selain pengaruh anatomis, tingkat stress yang diakibatkan rasa kekhawatiran, tekanan dan pengaruh psikologis lain selama hamil menjadi faktor pendukung terjadinya nyeri punggung. Rangsangan stress menstimulasi otot-otot menjadi menegang sehingga memicu timbulnya nyeri.

Kecemasan pada ibu hamil akan berpengaruh terhadap timbulnya penyakit serta komplikasi kehamilan dan persalinan, baik pada ibu maupu bayi. Faktor psikologis mempunyai pengaruh terjadinya gangguan saat proses persalinan. Kejadian persalinan lama sekitar $65 \%$ disebabkan karena kontraksi uterus yang tidak efisien, kontraksi uterus yang tidak adekuat sebagai respon terhadap kecemasan sehingga menghambat aktifitas uterus. Respon tersebut merupakan bagian dari komponen psikologis sehingga dapat dinyatakan bahwa besar pengaruh faktor psikologis dalam keselamatan menjelang persalinan pada ibu (Rusmita T Eli, 2011). Kecemasan pada masa hamil juga merupakan prediktor terjadinya depresi pasca persalinan (Milgrom et al., 2008; Verreault et al., 2014).

Edukasi dianggap cara terbaik dalam mempersiapkan persalinan (Ip et al., 2003). Materi persalinan yang diberikan dalam edukasi memberikan gambaran kepada ibu 
bagaimana proses persalinan dan memberikan gambaran kepada suami apa yang harus dilakukan dalam mendukung ibu bersalin. Edukasi pada ibu hamil dapat mempengaruhi cara persalinan (Afshar et al., 2017). Ibu yang mendapatkan dukungan pada masa persalinan akan berpeluang untuk bisa melahirkan normal lebih tinggi dan minimal intervensi. (Hodnett et al., 2014).

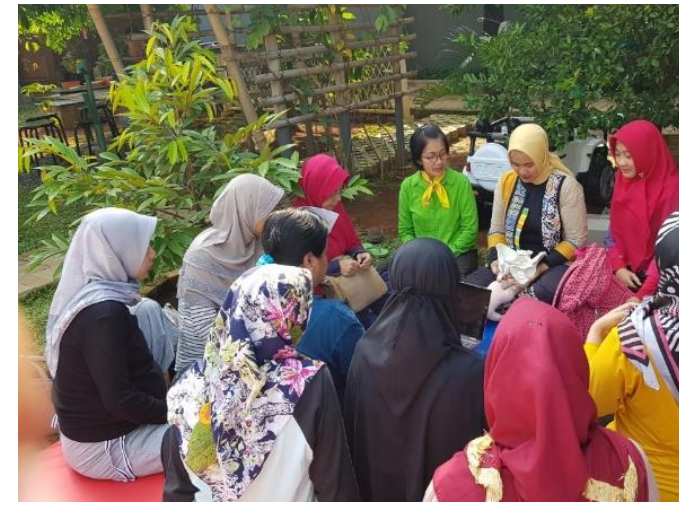

Gambar 1. Sesi praktek outdoor

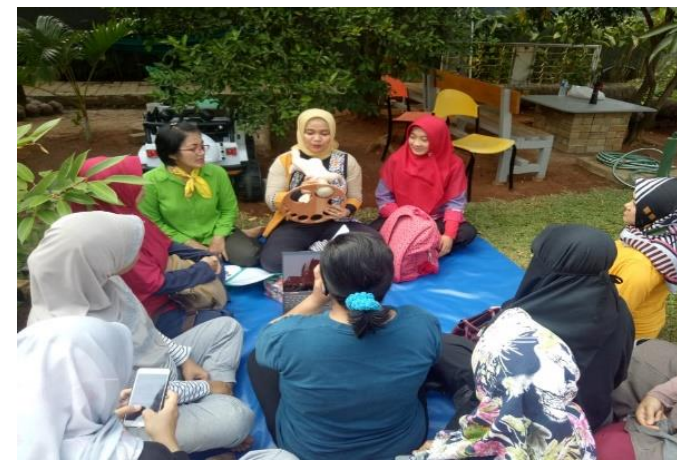

Gambar 3. Sesi praktek outdoor

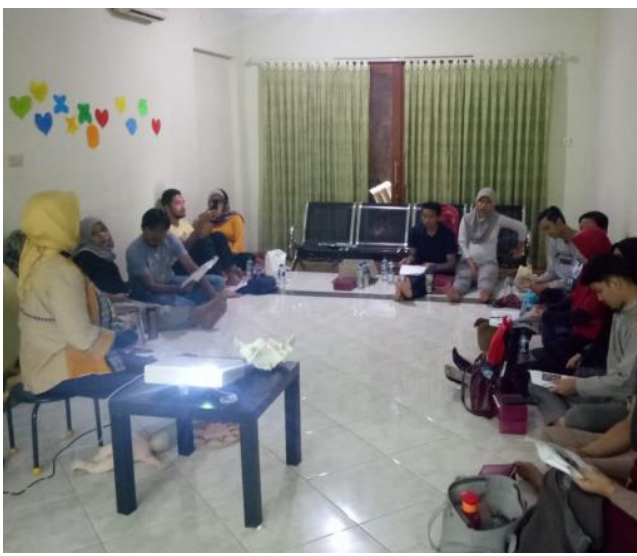

Gambar 5. Sesi presentasi indoor

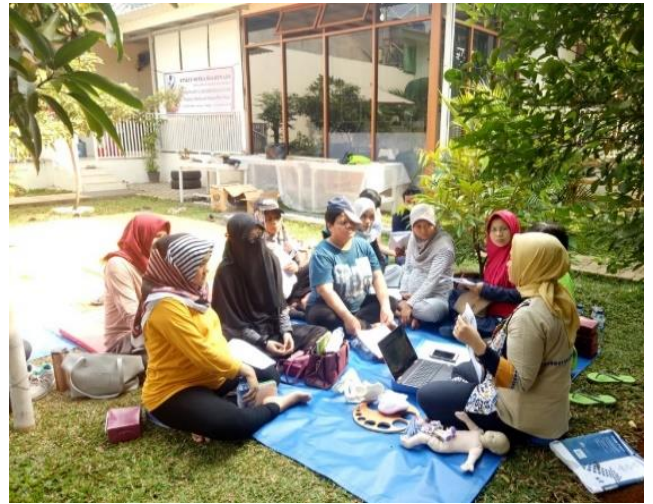

Gambar 2. Sesi praktek outdoor

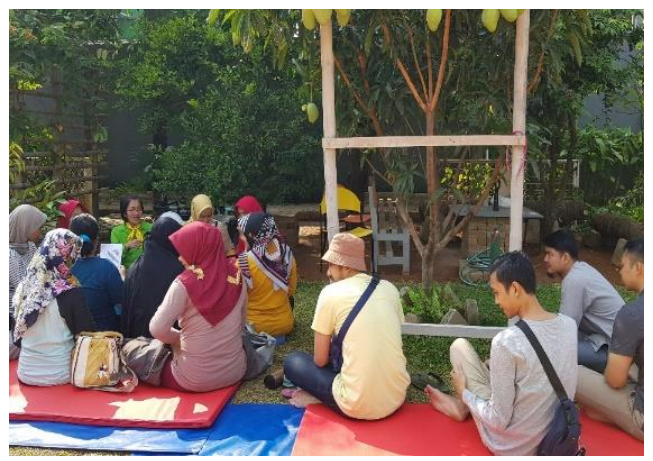

Gambar 4. Sesi praktek outdoor

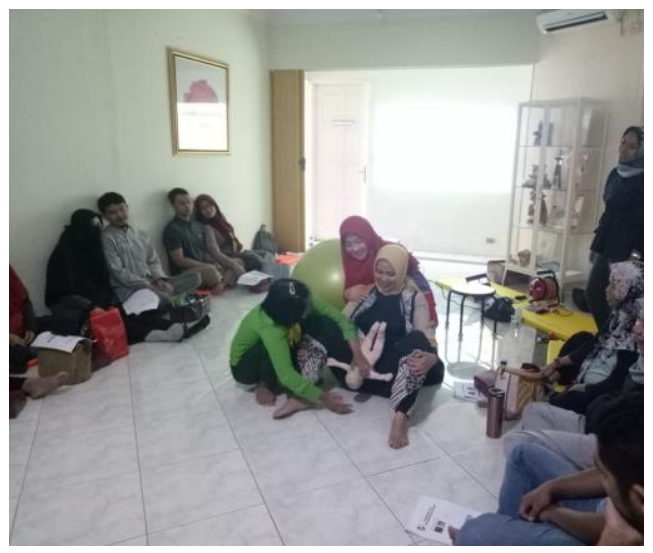

Gambar 6. Sesi praktek indoor 


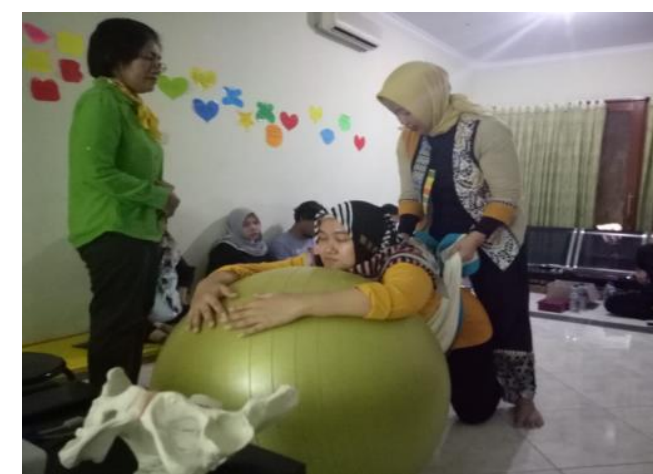

Gambar 7. Sesi praktek indoor

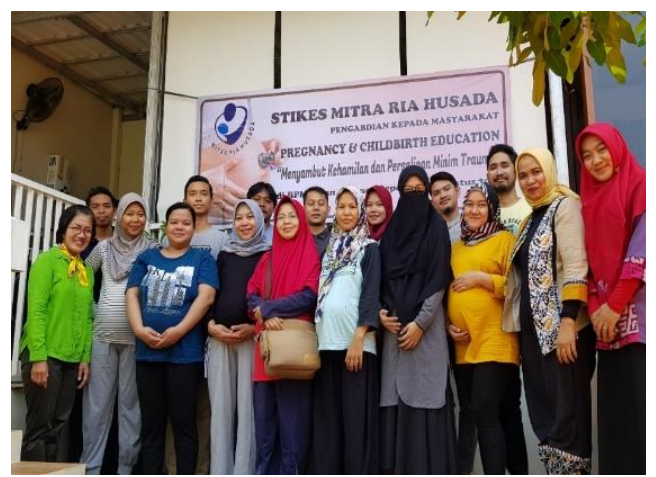

Gambar 8. Foto bersama

\section{KESIMPULAN}

Pelaksanan pengabdian kepada masyarakat sudah diselenggarakan dengan baik dan berjalan dengan lancar. Peserta terdiri dari delapan pasangan ibu hamil dengan usia kehamilan 26 minggu sd 36 minggu. Penyelenggaraan pengabdian kepada masyarakat ini dilaksanakan secara moving class dan practical. Peserta sangat antusias dan banyak bertanya. Saran dari pelaksanaan pengabdian kepada masyarakat ini adalah hendaknya kelas edukasi dapat dilaksanakan secara periodik sehingga lebih banyak lagi pasangan yang teredukasi dan siap menghadapi kehamilan dan persalinan dengan nyaman dan minim trauma.

\section{DAFTAR PUSTAKA}

Afshar, Y., Wang, E. T., Mei, J., Esakoff, T. F., Pisarska, M. D., \& Gregory, K. D. (2017). Childbirth Education Class and Birth Plans Are Associated with a Vaginal Delivery. Birth, 44(1), 29-34. https://doi.org/10.1111/birt.12263

Akca, A., Corbacioglu Esmer, A., Ozyurek, E. S., Aydin, A., Korkmaz, N., Gorgen, H., \& Akbayir, O. (2017). The Influence of The Systematic Birth Preparation Program on Childbirth Satisfaction. Archives of Gynecology and Obstetrics, 295(5), 1127-1133. https://doi.org/10.1007/s00404-017-4345-5

Bobak, L., Lowdermilk, D., \& Jensen, M. (2005). Buku Ajar Keperawatan Maternitas. In Jakarta:

EGC.https://scholar.google.com/scholar?as_q=perawatan+maternitas\&as_ep $\mathrm{q}=\mathbb{E a s} \_o q=\&$ as_eq=edas_occt=any\&as_sauthors=\&as_publication=\&as_ylo=\&as _yhi=\&btnG=\&hl=en\&as_sdt=0\%2C5\#2

Brixval, C. S., Axelsen, S. F., Lauemøller, S. G., Andersen, S. K., Due, P., \& Koushede, V. (2015). The effect of antenatal education in small classes on obstetric and psycho-social outcomes a systematic review. Systematic Reviews,4(1),20. https: //doi.org/10.1186/s13643-015-0010-x

Byrne, J., Hauck, Y., Fisher, C., Bayes, S., \& Schutze, R. (2014). Effectiveness of a Mindfulness-Based Childbirth Education Pilot Study on Maternal Self-Efficacy and Fear of Childbirth. Journal of Midwifery \& Women's Health, 59(2), 192197. https://doi.org/10.1111/jmwh.12075

Hodnett, E. D., Gates, S., Hofmeyr, G. J., \& Sakala, C. (2014). Continuous support 
for women during childbirth. Cochrane, 10(i), 1-59. https: //doi.org/10.1002/14651858.CD003766.pub4.Continuous

Ip, W. Y., Chien, W. T., \& Chan, C. L. (2003). Childbirth Expectations of Chinese First-Time Pregnant Women. Journal of Advanced Nursing, 42(2), 151-158. https://doi.org/10.1046/j.1365-2648.2003.02598.x

Irianti, B., Halida, E. M., Duhita, F., Prabandari, F., Yulita, N., Hartiningtiyaswati, S., \& Anggraini, Y. (2014). Asuhan Kehamilan Berbasis Bukti (F. Husin (ed.); 1st ed.). CV Sagung Seto.

Kemenkes. (2013). Riset Kesehatan Dasar ( RISKESDAS ) 2013.

Milgrom, J., Gemmill, A. W., Bilszta, J. L., Hayes, B., Barnett, B., Brooks, J., Ericksen, J., Ellwood, D., \& Buist, A. (2008). Antenatal risk factors for postnatal depression: A large prospective study. Journal of Affective Disorders, 108(1-2), 147-157. https://doi.org/10.1016/j.jad.2007.10.014

Miquelutti, M. A., Cecatti, J. G., \& Makuch, M. Y. (2013). Antenatal Education and The Birthing Experience of Brazilian Women: a Qualitative Study. BMC Pregnancy and Childbirth, 13(1), 171. https://doi.org/10.1186/1471-2393-13171

Mochtar, R. (2011). Sinopsis Obstetri (3rd ed.). EGC.

Rusmita T Eli. (2011). Pengaruh Senam Hamil Yoga Selama Kehamilan terhadap Kesiapan Fisik dan Psikologis dalam Menghadapi Persalinan pada Ibu Hamil Trimester III di RSIA Limijati Bandung. Universitas Indonesia.

Serçekuș, P., \& Bașkale, H. (2016). Effects of Antenatal Education on Fear of Childbirth, Maternal Self-Efficacy and Parental Attachment. Midwifery, 34, 166-172. https: //doi.org/10.1016/J.MIDW.2015.11.016

Sunarti, M., \& Soejono, S. K. (2012). Konseling dan Mekanisme Koping Ibu Bersalin. Journal of Educational Health and Community Psychology, 1(1), 1.

Verreault, N., Da Costa, D., Marchand, A., Ireland, K., Dritsa, M., \& Khalifé, S. (2014). Rates and risk factors associated with depressive symptoms during pregnancy and with postpartum onset. Journal of Psychosomatic Obstetrics and Gynecology, 35(3), 84-91. https: / / doi.org/10.3109/0167482X.2014.947953 